\title{
REVIEW
}

\section{Role of the human papilloma virus in the development of cervical intraepithelial neoplasia and malignancy}

\author{
A M Jastreboff, T Cymet
}

Postgrad Med J 2002;78:225-228

Human papilloma virus (HPV) is a public health problem as a sexually transmitted disease and as a critical factor in the pathogenesis of various cancers. The clinical manifestations, epidemiology, and virology that are critical to understanding the process of cervical dysplasia and neoplasia are reviewed. A discussion of the cervical transformation zone and the classification of cervical dysplasia and neoplasia leads into the importance of the Papanicolaou smear in prevention of potentially devastating sequelae of this virus. The role of the immune system in the progression of the disease and how it relates to vaccines, as well as treatment and prevention of HPV, are reviewed.

See end of article for authors' affiliations

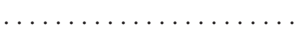

Correspondence to: Dr Tyler Cymet, Johns Hopkins School of Medicine, 2435 West Belvedere Ave, Suite 22, Baltimore, MD 21215 ,

USA; Tcymet@

Sinai-Balt.com

Submitted 5 June 2001

Accepted

22 October 2001
$\mathrm{V}$ iruses, from the Latin "slime" or "poisonous juice" were not understood as unique entities until the 19th century. ${ }^{1}$ The major development that lead to understanding viruses occurred in 1884 when Chamberland created a filter with pores small enough to retain bacteria, yet large enough for viruses to pass through. ${ }^{1}$ A century later, in the 1950s, a variety of viral particles were documented by electron microscopy. ${ }^{2}$

Papilloma virus was initially isolated from cottontail rabbits in 1933..$^{3}$ In 1935 it was discovered that papillomas induced by papilloma virus had the potential to transform into malignant processes. ${ }^{2}{ }^{4}$ Squamous cells that developed from human papilloma virus (HPV) lesions were noted in 1956. ${ }^{5}$ The authors called these cells koilcytotic atypia or koilocytosis, meaning "hollow", from the Greek word koilos. ${ }^{5}$ Before the invention of cloning techniques in the 1970s, investigation of HPV was difficult since the virus does not grow in culture. $^{6}$ Zur Hausen cloned the potentially malignant HPV 16 in the 1980s. ${ }^{6}$ By the end of the 20th century, over 100 types of HPV were identified.

HPV is recognised as a public health problem for its role as a sexually transmitted disease and also as a critical factor in the pathogenesis of various cancers. HPV is a crucial element in the development of cervical cancer, the third most common malignancy in women. ${ }^{7}$ The cause and effect relationship between HPV and cervical cancer is compelling. HPV DNA has been found in $90 \%$ of cervical cancer and $50 \%$ of vulvar cancer. ${ }^{8}$ Fifty per cent of young, sexually active women are infected with HPV types that may promote the development of cancer. ${ }^{9}$ In fact, HPV 16 and 18 have been classified as "carcinogenic" by the
World Health Organisation International Agency for Research on Cancer. ${ }^{7}$

\section{CLINICAL PRESENTATION}

HPV infection is initially asymptomatic ${ }^{10}$ and transmission between people occurs before overt expression of the virus is seen or felt. Clinically, HPV infects the basal cells of the epithelium ${ }^{11}$ of skin and mucous membranes. ${ }^{12}$ Because HPV may affect sites where there are epithelial cells, ${ }^{13}$ infections have been documented in the oral mucosa, oesophagus, larynx, trachea, conjunctiva, ${ }^{14}$ as well as genital and anal areas. ${ }^{12}$ HPV has not been identified in gastrointestinal mucosa. ${ }^{15}$

Infection may present in various ways. Latent HPV may be asymptomatic identified only by molecular biology techniques, or subclinical, seen on colposcopy. ${ }^{14}$ The virus may present as hyperplastic, hyperkeratotic warts or dysplastic lesions that may undergo neoplastic transformation. ${ }^{14}$

Non-genital warts may be passed on by fomites or direct contact with even a small area of broken skin. ${ }^{12}$ Alternatively, genital warts are passed on through direct contact with the lesion. ${ }^{12}$ Genital warts in females appear initially on the posterior introitus and adjacent labia; the warts then spread to the vulva, and eventually to the vagina and cervix. ${ }^{12}$ Genital warts can cause intense discomfort with associated pruritis, bleeding, and secondary infection caused by superficial injury due to scratching. ${ }^{12}$

Perhaps more important than the initial wart lesions that recur over the years, are the consequences of the latent infection with this virus - that is, dysplasia, neoplasia, and cervical cancer that occurs in a significant portion of these women. Important questions to ask include: Why do some women carry HPV for years with minimal sequelae while others are afflicted with carcinoma in situ? How can we prevent the spread of this potentially fatal virus? What is the role of the Papanicolaou (PAP) smear in the prevention of the more detrimental outcomes of this virus?

\section{EPIDEMIOLOGY}

Just under half of the $100 \mathrm{HPV}$ types identified infect the genital tract. ${ }^{6}$ Of these viral types only a small number have been detected in malignant lesions-that is, HPV 16, 18, 26, 27, 30, 31, 33-35,

Abbreviations: ASCUS, atypical squamous cells of undetermined significance; CIN, cervical intraepithelial neoplasm; HPV, human papilloma virus; HSIL, high grade squamous intraepithelial lesions; LSIL, low grade squamous intraepithelial lesions; PAP, Papanicolaou (smear) 


\section{Box 1: Cervical cancer}

\section{Risk factors}

- Increased number of sexual partners.

- Increased frequency of intercourse.

- Early age of first intercourse.

- Prostitution.

- Sexual behaviour of male partner.

\section{Associated risk factors}

- Tobacco smoking (nicotine metabolites identified in cervical mucous of female smokers)

- Use of oral contraceptives.

- Infection with other sexually transmitted diseases.

- High parity.

- Lack of certain nutritional factors (that is, as vitamin $\mathrm{C}$ or $\beta$-carotene)

$39,40,42-45,51-59,61,62,64,66-69$, and 71-74. ${ }^{14}{ }^{15}$ HPV 16 is the most malevolent and has been found in about $50 \%$ of cervical cancers throughout the world. ${ }^{6}$ Many other HPV types are responsible for benign warts, two of these types include HPV 6 and $11 .{ }^{14}$ There are geographic differences in the prevalence of HPV types in different regions worldwide. In Western Africa, HPV 45 is more prevalent, while in Central and South America HPV 39 and 59 are clustered, and in the Pacific Basin types 52 and 58 are dominant. ${ }^{6}$ Permeating through these clusters of potentially oncogenic types of HPV is the disproportionate higher prevalence of HPV $16 .{ }^{6}$

HPV infection has been increasing since the 1960s and is thought to be do to the increased use of oral, rather than barrier, forms of contraception. ${ }^{16}$ As HPV has been identified in $90 \%$ of cervical cancer, ${ }^{8}$ it is considered to be a risk factor of significant importance in the development of this malignancy. Other risk factors for the development of cervical cancer are elucidated in box $1 .^{716}$

Subtypes share less than $50 \%$ genomic homology with other HPV types and by having less than $90 \%$ homology in the nucleotide sequence of genes E6, E7, and L1 open reading frame with other papillomaviruses. ${ }^{17}$

\section{VIROLOGY}

The HPV virus is a non-enveloped, double stranded, circular DNA virus made of 7900 base pairs from the family Papovaviridae, genus papillomavirus. ${ }^{2}{ }^{12}$ It has an icosahedral capsid made of 72 capsometers and is $50-55 \mathrm{~nm}$ in diameter. ${ }^{212}$ Understanding the genomic organisation of HPV is crucial in understanding the oncogenic process it induces in the development of cervical dysplasia. Significant regions include the early region (E), the late region $(\mathrm{L}),{ }^{13}$ and the long control region. ${ }^{14}$ $\mathrm{E} 1$ and E2 are responsible for viral DNA replication and gene expression. ${ }^{2} \mathrm{Ll}$ encodes the capsid protein which makes up $95 \%$ of the viron mass, ${ }^{2}$ whereas L2 encodes for the minor capsid protein. ${ }^{2}$ E6 and E7 in essence immortalise the human keratinocytes. ${ }^{15}$ E6 mediates degeneration of p53 tumour suppressor protein while E7 binds retinoblastoma gene products. ${ }^{6}$ The sequence of events which disturb the normal apoptotic process of cervical cells, thus transforming them into immortal dysplastic cells, is as follows: circular viral DNA integrates E1/E2 region; as E2 is split and inactivated E6 and E7 products are enhanced; this leads to inactivation of $\mathrm{p} 53$ and $\mathrm{pRB}$ which in turn leads to cell cycle progression ${ }^{2}$ and immortalisation of normal cervical cells.

The HPV virus has an incubation period of three to four months. ${ }^{12}$ The virus infects the basal cells, virons assemble in the nucleus, and subsequently are released as keratinocytes are shed. ${ }^{12}$ There is proliferation of all epidermal layers, except the basal layer. ${ }^{12}$ Products of this proliferation include acanthosis, parakeratosis, and hyperkeratosis that then clinically manifest as condylomata acuminata or genital warts. ${ }^{12}$

\section{CERVICAL DYSPLASIA}

The cervical transformation zone is of particular significance as it is the location where cervical dysplasia most often occurs. ${ }^{10}$ The cervix is made up of two histologically unique parts. The endocervix, which is predominantly comprised of columnar cells, and the exocervix, which is made up of squamous cells. ${ }^{10}$ The transformation zone, also called the squamocolumnar junction, is the area of the cervix where the exocervix and endocervix meet. ${ }^{10}$ Starting during puberty, the columnar cells of the endocervix slowly transform into squamous cells, thus it is said that the exocervix "moves in" towards the cervical os. ${ }^{10}$

Classification of dysplastic lesions is also an important issue. Depending on the time of publication, various sources use different descriptions and classification systems. In the 1940s, cervical abnormalities were described by Papanicolaou who devised a five class system (I to V), ${ }^{16}$ which included mild, moderate, and severe dysplasia, carcinoma in situ, and cancer. ${ }^{6}$ In the late 1960s, Richart created a new classification of dysplasia where changes were termed cervical intraepithelial neoplasia (CIN) I, II, and III. ${ }^{6}$ It was thought that a progression of events occurred as patients advanced sequentially through these stages on a continuum from CIN I to carcinoma in situ. ${ }^{18}$

As cervical dysplasia was studied more closely it became evident that it did not follow a straightforward progression. With a diagnosis of CIN I, about $1 \%$ progress to invasive carcinoma. ${ }^{19}$ The transformation from CIN I to CIN II occurs very quickly, with about $5 \%$ on CIN II progressing to invasive cancer. ${ }^{19}$ Evidence indicates that CIN III does in fact have a significant risk ( $>12 \%$ ) of progressing to invasive carcinoma if left untreated ${ }^{19}$ The treatment for CIN II and III is essentially the same and, therefore, clinically did not warrant separate categories. In addition, this system of classification was not utilised uniformly throughout academic institutions and other more descriptive classifications continued to be used. A uniform classification system was needed for algorithms of treatment protocols and for groupings in scientific studies.

Created in 1988 and revised in 1991, the Bethesda system for rating cytology accomplished these goals and continues to be in current use. ${ }^{6}$ This system includes the following classes: atypical squamous cells of undetermined significance

Table 1 The Bethesda system for rating cytology

\begin{tabular}{llll}
\hline Bethesda system & Description & $\begin{array}{l}\text { Papanicalou } \\
\text { classification }\end{array}$ & $\begin{array}{l}\text { Cervical intraepithelial } \\
\text { neoplasia }\end{array}$ \\
\hline ASCUS & Atypical squamous cells of undetermined significance \\
LSIL & Low grade squamous intraepithelial lesions & $\begin{array}{l}\text { Squamous atypia } \\
\text { Mild dysplasia, koilocytic or } \\
\text { condylomatous atypia }\end{array}$ & $\begin{array}{l}\text { Papanicolaou class II } \\
\text { Papanicolaou class III }\end{array}$ CIN I \\
HSIL & High grade squamous intraepithelial lesion & Moderate to severe dysplasia & Papanicolaou class IV CIN II \\
& & & CIN III \\
\end{tabular}


(ASCUS), low grade squamous intraepithelial lesions (LSIL), high grade squamous intraepithelial lesions (HSIL), and carcinoma in situ (see table 1). ${ }^{2711} 1620$

\section{ROLE OF THE PAP SMEAR}

The Papanicolaou smear is based on the work of a Greek physician, George N Papanicolaou. ${ }^{21}$ Papanicolaou first began to study normal and abnormal vaginal cytology in the 1920s. ${ }^{18}$ He published his findings with Herbert Traut, a gynaecological pathologist, in 1941 in The diagnostic value of vaginal smears in carcinoma of the uterus. ${ }^{22}$ Named after its creator, today the vaginal smear is known as the PAP smear.

Unfortunately, there has never been an evaluation of PAP smear screening in a randomised control trial. ${ }^{16}$ The data regarding screening is based on differences seen geographically over the time that the PAP smear has been used. ${ }^{16}$ Overall, the PAP has decreased the rate of stage II squamous cell carcinoma in women that are regularly screened but has not been shown to decrease the rate of adenocarcinoma or adenosquamous carcinoma. ${ }^{16}$ The American College of Obstetrics and Gynecology recommends that PAP smear screening should start at age 18 or when the woman becomes sexually active. ${ }^{23}$ The recommendation is to continue annual screening until three normal PAP smears have been obtained; at this time, if the physician prefers, the women may be tested less frequently. ${ }^{23}$ There is no consensus as of yet at to what age to stop PAP smear screening, but since cervical cancer may be diagnosed postmenopausally, individual risk factors must be taken into consideration. ${ }^{23}$ The American Academy of Family Physicians recommends discontinuation of PAP smear screening after age 65 if the woman does not have a history of positive PAP smears. ${ }^{24}$ In women who have had hysterectomies the incidence of cervical cancer is extremely low. Therefore if the uterus was removed for benign reasons, the cervical epithelium was completely removed, and the woman had no previous abnormal PAP smear findings, screening may be discontinued. ${ }^{23}$

\section{ROLE OF THE IMMUNE SYSTEM IN THE PROGRESSION OF HPV TO CERVICAL DYSPLASIA}

Why does cervical dysplasia undergo a malignant transformation in some women but not others? It appears that the immune system plays a significant part in the regression or progression of cervical dysplasia. One study suggested that CD8 cells against HPV antigen were more prevalent in women without cervical dysplasia than in women with cervical dysplasia. ${ }^{10}$ Also antibody levels in persistent HPV are increased in chronic HPV infection and there is evidence of T-cell recruitment to the site of HPV infection. ${ }^{10}$ In addition, CD8 tumour infiltrating lymphocytes have been found in cervical cancer. ${ }^{10}$ To examine the role of the immune system in HPV, scientists have examined immunocompromised women with HIV. One such study, published in March 2001, confirmed that women infected with HIV had an increased incidence of squamous intraepithelial lesion due to an increased risk of infection with HPV as well as due to the depressed immune states. ${ }^{25}$ In this study, in women infected with HIV the prevalence of ASCUS was found to be 1.8 times greater and squamous intraepithelial lesion was 3.9 times greater than that of women who did not have HIV. ${ }^{25}$ It is evident in this patient population that there is in fact a more rapid and increased incidence of HPV caused cervical dysplasia and therefore, a depressed immune system may lead to decreased ability to suppress the progression to dysplastic lesions.

\section{TREATMENT}

The treatment of cervical dysplasia may be complicated, reflecting differences in algorithms used at various institutions and distinct treatments for varied degrees of dysplasia.
For example, in a compliant patient with ASCUS and minimal risk factors it may be suggested to repeat the PAP smear within three to six months. ${ }^{2}$ If the repeat PAP smear is positive the patient should undergo colposcopy. ${ }^{2}$ If compliance is questionable in a patient with ASCUS, the patient may undergo colposcopy with an endocervical biopsy without obtaining the repeat PAP smear beforehand.

LSIL may be observed or excised, where as HSIL should be biopsied using colposcopy. ${ }^{7}$ Further treatment of HSIL includes various procedures to obliterate the potentially malignant cells. Cryosurgery is the ablation of the dysplastic lesion, using cold in the form of liquid nitrogen. Laser ablation is the use of heat to burn away the dysplasia. Surgical excision is the process of making a cone biopsy and actually removing a wedge of the cervix. There are also medical treatments that include the use of topical antimetabolites (5-fluorouracil) or interferon. It is important to understand that each of these forms of treatment may at best prevent the progression of cervical dysplasia to cancer but none of these treatments are a cure for the virus itself. Therefore, it is important to discuss prevention, the only known "cure" for HPV infection.

\section{PREVENTION}

First, it is important to counsel patients on the environmental risk factors that may predispose them to becoming infected with the HPV virus. If a patient decreases the number of sexual partners she has, she will then decrease the probability of becoming infected with HPV. In addition, although HPV may be spread even if a barrier method is used, the use of barrier contraceptives decreases the probability that the patient will become infected. Annual PAP smears have become a crucial tool in decreasing mortality from cervical cancer. Mortality from cervical cancer has decreased by over $40 \%$ since the start of PAP smear screening in the United States. ${ }^{23}$ This decrease in mortality occurs because the lesions are detected early on when they are still treatable.

Promising future forms of treatment are various HPV vaccines. There are several forms of HPV vaccines/cervical cancer vaccines that are currently under investigation. The transfer of cytotoxic T-lymphocytes has been successful in eliminating certain tumours in mice. ${ }^{26}$ Peptide based vaccines have been shown to activate antigen specific cytotoxic T-cells. ${ }^{26}$ Virus-like particles, for example containing only the major capsid protein, may potentially be used as a prophylactic vaccine and have shown to produce humoral immunity in mice. ${ }^{26}{ }^{27}$ Vaccination with a vector encoding for HPV has produced humoral and cell mediated responses in mice which DNA vaccines have shown a similar response in rabbits. ${ }^{26}$ Many of these studies are still at the level of animal based models therefore it may be years before scientists create what would be the ideal HPV vaccine; one which would have preventative as well as therapeutic faculties.

\section{CONCLUSION}

In conclusion, HPV is a significant public health problem as a sexually transmitted disease and more importantly as a crucial contributing factor to the development of cervical cancer. Consequently, PAP smear screening has become a crucial part of women's health as early detection of cervical dysplasia has significantly reduced the morbidity and mortality of cervical cancer in the United States. Therefore, it is not only necessary for physicians to continue PAP smear screening on women who present for the "annual well women exam", but it is also vital to target women who present to the clinic for other health problems; women who would otherwise not be screened for potentially devastating sequelae.

Authors' affiliations

A M Jastreboff, University of Maryland School of Medicine

T Cymet, Family Medicine, Sinai Hospital of Baltimore 


\section{REFERENCES}

1 Porter R. The greatest benefit to man kind: a medical history of humanity. New York: W W Norton, 1997.

2 Kaufman RH, Adam E, Vonka V. Human papillomavirus infection and cervical carcinoma. Clin Obstet Gynecol 2000;43:363-80.

3 Shope RE, Hurst EW. Infectious papillomatosis of rabbits, with a note on histopathology. J Exp Med 1933;58:607-24.

4 Rous PJB. The progression of carcinoma of virus-induced papillomas (Shope). J Exp Med 1935;62:523-48.

5 Koss LG, Durfee GR. Unusual patterns of squamous epithelium of the uterine cervix: cytologic and pathologic study of koilocytic atypia. Ann N Y Acad Sci 1956:63:1245-61.

6 Burk RD. Human papillomavirus and the risk of cervical cancer. Hosp Pract 1999;34:103-11.

7 Franco EL, Duarte-Franco E, Ferenczy A. Cervical cancer: epidemiology, prevention and the role of human papillomavirus infection. Can Med Assoc J 2001; 164:1017-25.

8 Brewster WR, Monk BJ, Burger RA, et al. Does human papillomavirus have a role in cancer of the uterine corpus? Gynecol Oncol 1999;75:51-4.

9 Galloway DA. Is vaccination against human papillomavirus a possibility? Lancet 1998;351(suppl 3):22-4.

10 Kobayashi A, Miaskowski C, Wallhagen M, et al. Recent developments in understanding the immune response to human papilloma virus infection and cervical neoplasia. Oncol Nurs Forum 2000;27:643-51.

11 Moscicki AB. Human papillomavirus infection in adolescents. Pediatr Clin North Am 1999;46:783-807.

12 Harrison's principles of internal medicine. 14th Edition on CD-ROM. New York: McGraw-Hill, 1999.

13 Alani RM. Munger K. Human papillomaviruses and associated malignancies. J Clin Oncol 1998;16:330-7.

14 Tyring SK. Human papillomavirus infection: epidemiology, pathogenesis, and host immune response. J Am Acad Dermatol 2000;43(1 pt 2):S18-26.
15 Zur Hausen H. Papillomaviruses causing cancer: evation from host-cell control in early events in carcinogenesis. J Natl Cancer Inst 2000;92:690-8.

16 Sigurdsson K. Cervical cancer, Pap smear and HPV testing: an update of the role of organized Pap smear screening and HPV testing. Acta Obstet Gynecol Scand 1999;78:467-77.

17 Goodman A. Role of routine human papillomavirus subtyping in cervical screening. Curr Opin Obstet Gynecol 2000;12:11-4.

18 Ehrmann RL. Benign to malignant progression in cervical squamous epithelium. New York: IGAKU-SHOIN Medical Publishers, 1994

19 Pinto AP, Crum CP. Natural history of cervical neoplasia: defining progression and its consequence. Clin Obstet Gynecol 2000;43:352-62.

20 Kaufmann RH, Adam E. Is human papillomavirus testing of value in clinical practice? Am J Obstet Gynecol 1999;180:1049-53.

21 Stedman's concise medical dictionary. 26th Ed. Baltimore: Willams \& Wilkins, 1997.

22 Papanicolaou GN, Traut HF. The diagnostic value of vaginal smears in carcinoma of the uterus. Am J Obstet Gynecol 1941;42:192-206.

23 Zanotti KM, Kennedy AW. Screening for gynecological cancer. Med Clin North Am 1999;83(6).

24 US Preventive Service Task Force. Guide to clinical preventive service. 2nd Ed. Baltimore: Williams \& Wilkins, 1996.

25 Duerr A, Kieke B, Warren D, et al. Human papillomavirus-associated cervial cytologic abnormalities amoung women with or at risk of infection with human immunodeficiency virus. Am J Obstet Gynecol 2001;184(4).

26 Van Driel WJ, Kenter GG, Fleuren, GJ, et al. Immunotherapeutic strategies for cervical squamous carcinoma. Hematol Oncol Clin North Am 1999;13(1).

27 Schiller JT. Papillomavirus-like particle vaccines for cervical cancer. Molecular Medicine Today 1999;5(209). 